\title{
Paro Nacional: Agendas partidistas durante la crisis social en Ecuador
}

\section{Paro Nacional: political agendas that did} not answer for national interests among the social crisis inside Ecuador

Guillermo Andrade* 


\section{Resumen}

Acorde pasan los años, las palabras "desarrollo", "agenda nacional" e "integración" en el Ecuador empiezan a poseer menos sentido material, más aún cuando los líderes políticos, futuros y vigentes, manejan discursos públicos y agendas ideológicas de separación y culpabilidad frente a otros actores. El Paro Nacional fue la expresión más clara de la fragmentación social que vive el país ecuatoriano, siendo este el indicador más cercano frente a las próximas elecciones presidenciales del 2021, donde los intereses partidistas alejan cada vez más la posibilidad de llegar a acuerdos nacionales debido a los incentivos por poseer más ventajas y beneficios. Lastimosamente, estos discursos refuerzan ciertas acciones populares, llegando así a comportamientos sociales negativos en todas las esferas legitimadas por autoridades, aparentemente encargadas de llegar a una inalcanzable unidad.

\section{Palabras clave:}

Agenda nacional, unidad, elecciones presidenciales, discursos, fragmentación social, partidismo. 


\section{Ahstract}

In Ecuador, words like development, national agenda or integration are losing their material sense because of the behavior that came from politicians and social leaders. All of those actors are having public speeches that promote separation and assert that other actors are guilty for the events. The "Paro Nacional" was the clearest expression of social fragmentation inside the country, letting us to know how is going to be the participation during the next presidential elections in 2021, a situation where the interests of the political parties will be bigger than the possibility of having national agreements between all the political actors inside Ecuador. Unfortunately, these speeches shape the political opinion, getting this into negative social behavior that damage different parts of the society and political authorities legitimate that.

\section{Keywords:}

National agenda, unity, presidential elections, narratives, social fragmentation, political militancy. 
El 01 de octubre del 2019, el presidente Lenín Moreno anunció por cadena nacional la aplicación de un paquete de medidas económicas, entre las cuales resaltaban la eliminación de los subsidios al combustible, recortes en beneficios laborales para los servidores públicos y compensaciones tributarias para el sector productivo, específicamente destinadas al agro (Política 2019a). Posterior al pronunciamiento, una cantidad significativa de la población, liderada inicialmente por los transportistas y a renglón siguiente por el movimiento indígena, decidió manifestarse en diferentes ciudades del país. Aunque no existe una cifra exacta de personas durante todo el periodo de movilizaciones, el Ministerio de Gobierno (2019) sí pudo determinar que aprehendieron a 1330 personas, se bloquearon 132 ejes viales y hubo 1507 personas atendidas por entidades cómo el Ministerio de Salud Pública, Instituto Ecuatoriano de Seguridad Social (IESS) y la Cruz Roja, siendo esto una evidencia para dimensionar el tamaño de la protesta.

Frente a los sucesos previamente expuestos, el

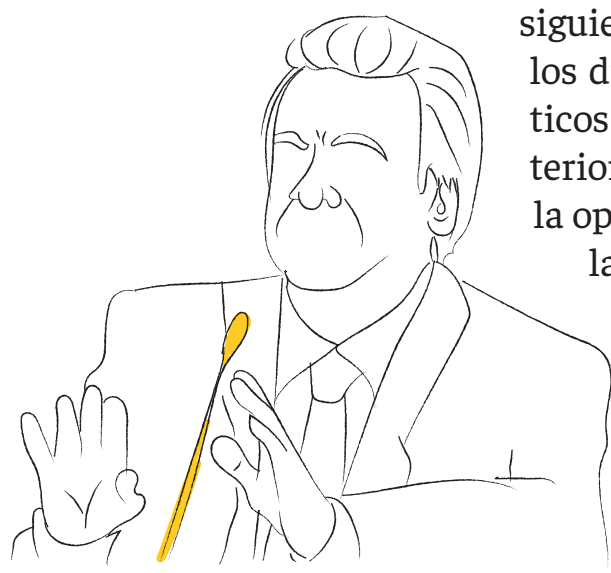
los discursos y el rol de diversos líderes políticos ecuatorianos, durante el conflicto y posterior al mismo, han moldeado y exacerbado la opinión sobre las injusticias que aquejan a las masas. Con lo que se generan comportamientos sociales negativos que limitan el acceso a objetivos nacionales de desarrollo y que perpetúan la carencia de consensos, a partir del seguimiento de intereses partidistas o agendas que buscan un objetivo en las elecciones del 2021.

Para un mejor entendimiento, se deben explicar ciertos conceptos, parte del contexto ecuatoriano y la importancia del consenso para la aceptación política. Así mismo, para el futuro análisis se empleará evidencia textual de los siguientes actores: las autoridades más visibles del Gobierno Nacional ecuatoriano, dirigentes de la Confederación de 
Nacionalidades Indígenas del Ecuador (CONAIE) y líderes sindicales, miembros de la sección Madera de Guerrero del Partido Social Cristiano y las figuras vigentes del correísmo. Quienes han sido tomadas en cuenta por su influencia histórica y participación activa durante las movilizaciones, ya sea desde el lado propositivo o en contra de las mismas. Dentro de los conceptos por clarificar, se tiene que identificar que el discurso político es un mensaje persuasivo que se pronuncia de manera pública para facilitar el entendimiento de cierta información al potencial elector o ciudadano común. Por otra parte, aunque en sentido muy amplio, pero en beneficio del lector, se define al comportamiento social negativo como la manera de proceder de un individuo que afecte y genere daños a la organización primordial de la sociedad, más aún con su integridad, diversidad cultural e intereses de desarrollo distintos.

El primer actor relevante se enfoca en el Gobierno Nacional del presidente Lenín Moreno, debido a que jugó el rol más complicado y de mayor exigencia durante la crisis. Específicamente, por ser el responsable de precautelar el orden y atender las quejas planteadas por los grupos participantes de las manifestaciones. Ante ello, autoridades como el vicepresidente Otto Sonnenholzner, quien no ganó elección democrática popular alguna, salieron a expresar que el Paro Nacional fue parte de una planificación para desestabilizar el accionar del Gobierno y que una cantidad relevante de extranjeros recibían bonos de 40 a 50 USD para participar de manera violenta durante las protestas.

A renglón seguido, indicó que "Un extranjero que no cumpla con las leyes no podrá seguir en Ecuador. Los sancionaremos con el peso de la ley" (Política 2019b.). Días después, la Fundación de Venezolanos en el Ecuador salió públicamente a denunciar la detención arbitraria de 17 venezolanos, dentro de las cuáles, dos de ellas, recayeron sobre conductores de UBER que se encontraban a las afueras del aeropuerto de Tababela durante las protestas (El Diario 2019). Es decir, la intención apresurada de buscar culpables sobre las movilizaciones ha generado un claro malestar en personas inocentes, refuerza discursos de xenofobia dentro del país y no brinda garantía alguna sobre el manejo de la justicia para cada uno de los ecuatorianos. Aspectos que claramente no aportan al desarrollo de 
una agenda nacional con responsabilidad para todos los que viven en el país, especialmente porque es esencial la tranquilidad de saber que existen procesos justos desde el Estado.

La CONAIE con sus líderes más representativos: Jaime Vargas y Leonidas Iza; tomaron la posta de la protesta y resurgieron al movimiento como el opositor más fuerte frente a las propuestas del Gobierno Nacional. Iza, frente a la coyuntura económica, indicó que "Una manera de mejorar la economía sería quitar los sueldos vitalicios y verá que el pueblo aplaudirá esta decisión" (Estrella 2019). Posteriormente también expresó que "las medidas económicas fueron una imposición del Fondo Monetario Internacional (FMI). Todo proceso interno debe tener legitimidad, y este proceso ha sido implementado por el FMI".

Vargas, por su parte, declaró que "no estaban para conformar comisiones con ministros 'vagos'” (Teleamazonas 2019). Ambas declaraciones, aunque sean aparentemente empáticas frente a las comunidades afectadas y tajantes con las autoridades, no reflejan más que soluciones esporádicas sin un impacto real en el presupuesto estatal a corto plazo (caso de sueldos vitalicios). Es decir, son parte de un discurso político que busca defender una posición de crítica frente a decisiones del Gobierno Nacional actuales, pero sin considerar el mal manejo de las finanzas públicas en años previos o ser consecuentes al presentar alternativas que sean viables e importantes para generar un cambio.

Resulta relevante añadir que, desde 1986, el movimiento indígena ha sido un actor intermitente, pero muy tajante dentro la participación política ecuatoriana, con principios de lucha estructurados frente al contexto en el que viven y promoviendo consignas que, en su momento, derrocaron o fueron claves para desestabilizar gobiernos, como los casos de Jamil Mahuad y Lucio Gutiérrez (Granja 2019). El gran descontento y malestar se continúa observando en la actualidad con la cruda realidad indígena; según datos publicados por la UNICEF, el 40\% de los niños y niñas indígenas menores de 5 años sufren de desnutrición y $60 \%$ de su población total vive (La Hora 2017). Su motivación de lucha en esta ocasión fue poco a poco deslegitimada por los medios de comunicación y parte de la opinión pública, debido al accionar violento durante las mo- 
vilizaciones de sus comunidades, específicamente después de retener a periodistas y policías dentro de la Casa de la Cultura. Por lo tanto, si el movimiento indígena quiere cambios que se mantengan a largo plazo deberá inmiscuirse en las prácticas del reformismo o de la construcción de un proyecto país. No obstante, por su contexto y situación conflictiva actual, tienen pocos incentivos para ceder sobre ciertas consignas que desean obtener.

Fuera de los actores "principales" del Paro Nacional, también aparecieron líderes políticos de diferentes partidos para expresar su opinión y presentar propuestas que concluyeron en intentos fallidos de solución. Más aún, al demostrar una clara prevalencia de sus intereses partidistas para volver al tablero político en vísperas a futuras elecciones. Especialmente al identificar claras contradicciones cuando se comparan sus discursos con acciones del pasado donde fueron parte del eje de poder estatal. Los más pronunciados fueron: el ex-presidente del país Rafael Correa y el ex-alcalde de Guayaquil Jaime Nebot. Ambos, mantuvieron un papel relevante con discursos, expresiones populares y textos por sus redes sociales frente a la mayoría de sucesos que envolvieron al Paro Nacional. Los comentarios que presentaban hacían contingencia con lo que consideraban como un mal manejo de la crisis por parte del Gobierno Nacional actual y respecto al accionar por parte de los movimientos indígenas.

Nebot en conjunto con Cinthya Viteri, desde Guayaquil, mencionaban que quitar los subsidios sería una medida que afectaría a las clases socio-económicas medias y más bajas, que los recortes deberían ser enfocados a otros sectores y que el aumento de impuestos por temas de patrimonio solo le quitará al pueblo lo que el Estado anteriormente

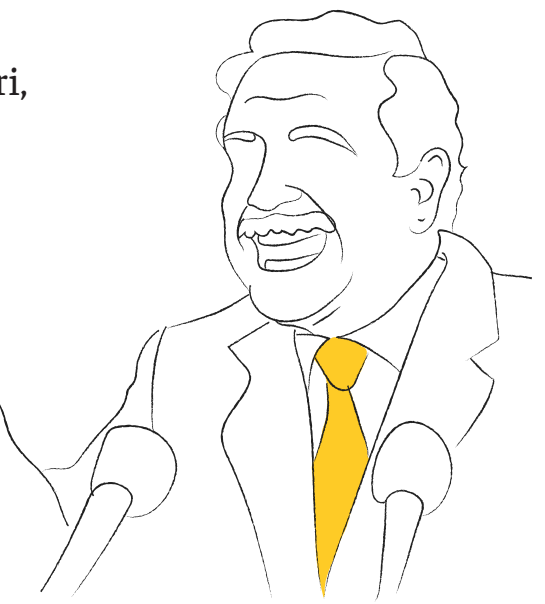


se "farreó". Es decir, aunque no justificaba la movilización indígena sí mostraba ser antagónico al decreto 883 y sus medidas económicas cercanas (Plan V 2019). Del otro lado, el ex-presidente Correa indicó el valor de la lucha indígena frente a un gobierno que, bajo su consideración, había traicionado al modelo de la Revolución Ciudadana y es el principal causante de la crisis económica. La contradicción aparece cuando se observa que durante su mandato la CONAIE y varios colectivos sociales sufrieron una de las persecuciones más fuertes y fraccionamientos más evidentes de la historia, con el fin de evitar las movilizaciones que ahora, por conveniencia, respaldó (Granja 2019).

En conclusión, el Ecuador vive una fragmentación social desde diferentes grupos de personas, ya sea con justificaciones cuestionables, pero existentes por sus intereses comunitarios, características socio-económicas o su nacionalidad. Situación que se ha venido incrementando a lo largo de los últimos años, y que ha tenido como catalizador el último Paro Nacional, porque ahora se puede plasmar con evidencias tangibles y afectaciones materiales las molestias de los ecuatorianos, dejando precedentes que se pueden analizar por el almacenamiento de material tecnológico. Frente a ello, los resultados y la transformación del discurso político se plasman de manera negativa. Inicialmente, porque desde las autoridades gubernamentales se presentan acciones impulsivas, carentes de principios y sin señales de tener un estado justo, más aún cuando está en juego la búsqueda de culpables en manifestaciones que responden a problemas estructurales que el gobierno debe responder.

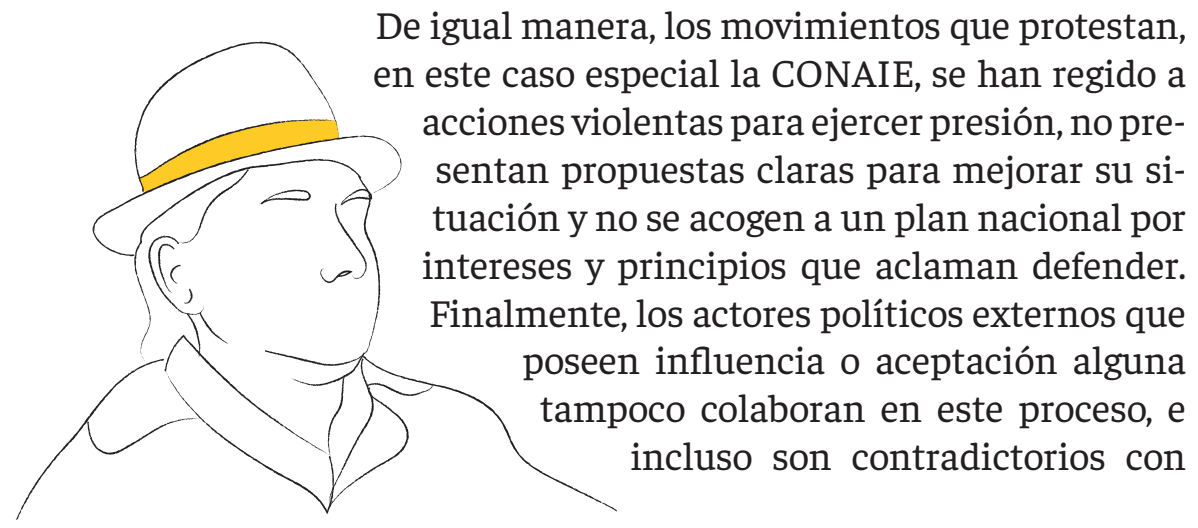


sus acciones pasadas o los intereses que aparentemente pretenden defender, generando así un discurso que se moldea acorde a la situación más favorable para seguir en el terreno político ecuatoriano. Cada uno de estos sucesos, desemboca en un escenario dónde no es posible construir nada positivo para los diferentes sectores de la sociedad, debido al costo político y las repercusiones que estas acciones puedan tener. 


\section{Referencias}

El Diario. 2019. "Venezolanos en Ecuador exigen una "disculpa pública" a la ministra de Gobierno tras arrestos." El Diario, octubre 17, 2019. http://www.eldiario.ec/ noticias-manabi-ecuador/511723-venezolanos-en-ecuador-exigen-una-disculpa-publica-a-la-ministra-de-gobierno-tras-arrestos/.

Estrella, Silva. 2019. “Leonidas Iza: “Debemos racionalizar los subsidies y eliminar los sueldos vitalicios." Pichincha Universal, octubre 13, 2019. http://www.pichinchauniversal.com.ec/leonidas-iza-debemos-racionalizar-los-subsidios-y-eliminar-los-sueldos-vitalicios/.

Granja, Carlos. 2019. "La Conaie, 33 años de historia de un movimiento clave en Ecuador." El Universo, octubre 12, 2019. https://www.eluniverso.com/noticias/2019/10/12/nota/7557206/conaie-protestas-ecuador-crisis-historia-movimiento-indigena.

La Hora. 2017. "Los indígenas siguen siendo la población más pobre del país." La Hora, marzo 02, 2017. https://lahora.com.ec/noticia/1102035236/los-indc3adgenas-siguen-siendo-la-poblacic3b3n-mc3als-pobre-del-pac3ads.

Ministerio de Gobierno. 2019. "1330 detenidos y 1507 heridos fue el resultado de las paralizaciones en el Ecuador." Boletín 41, octubre 15, 2019. https://www. ministeriodegobierno.gob.ec/1330-detenidos-y-1507-heridos-fue-el-resultado-de-las-paralizaciones-en-el-ecuador/.

Plan V. 2019 “El plan económico del gobierno: ¿ंGolpe a las clases medias?” Plan V, octubre 27, 2019. https://www.planv.com.ec/historias/economia/el-plan-economico-del-gobierno-golpe-clases-medias.

Política. 2019a. "Eliminación de subsidios a gasolina y diésel, entre medidas económicas del Gobierno de Ecuador." El Universo, octubre 1, 2019. https://www. eluniverso.com/noticias/2019/10/01/nota/7543657/eliminacion-subsidio-gasolina-diesel-medidas-economicas-gobierno.

2019b. "Otto Sonnenholzner: Sí retrocedemos lo único que peligra es la dolarización." El Universo, octubre 9, 2019. https://www.eluniverso.com/noticias/2019/10/09/nota/7553576/otto-sonnenholzner-si-retrocedemos-unico-que-peligra-es. 
Teleamazonas. 2019. "Leonidas Iza realiza un análisis en relación a los subsidios." Teleamazonas, octubre 16, 2019. http://www.teleamazonas.com/2019/10/leonidas-iza-realiza-un-analisis-en-relacion-a-los-subsidios/. 